\title{
Timeliness of earnings reported by Romanian listed companies
}

\author{
Mihai Carp ${ }^{\mathrm{a} 1}$ and Constantin Toma ${ }^{\mathrm{a}}$ \\ a “Alexandru Ioan Cuza” University of Iaşi, Romania
}

\begin{abstract}
The paper aims to analyze the quality of financial information, by assessing the timeliness of earnings, using information specific to non-financial companies listed on the regulated section of Bucharest Stock Exchange. The study also seeks to assess the symmetry of actions for the timely recognition of potential gains and losses (components of the economic income) and, if there is an asymmetry, to identify the sense of the temporary gap. The phenomenon is analysed in conjunction with a number of control factors such as the Romanian Accounting Standards (RAS), the International Financial Reporting Standards (IFRS), the degree of indebtedness or the entities' field of activity. Quantitative analysis performed through econometric models consecrated in the field, such as Basu (1997) and Ball and Shivakumar (2005), reveals that the companies included in the study provide financial information that meets the qualitatively criterion assessed, respectively earnings timeliness. Deepening the analysis has made it possible to identify a timely recognition both for unrealised gains and potential losses, as a result of tests carried out on the whole sample, an advance in what concerns the inclusion of economic lose in the accounting income compared to the recognition of economic gains. The presence of disjunctive factors in the analysis generated a number of particular results. In the case of normally indebted companies that apply the IFRS, a timely recognition of economic gains and losses was noted, without the gap specific to conservatism.
\end{abstract}

Keywords: financial information quality, timeliness of earnings, conservatism, IFRS, economic income

JEL codes: C13, C83, M41, M42

\footnotetext{
${ }^{1}$ Corresponding authors: Faculty of Economics and Business Administration, "Alexandru Ioan Cuza" University of Iaşi, Carol I Blvd, 11, 700506, Iasi Romania; tel.

(+40)742919961; email address: mihai.carp@feaa.uaic.ro
} 


\section{Introduction}

The utility for investors of financial information reported by business entities is conditional upon the latter's fulfilment of certain quality criteria. High quality financial reports mitigate information asymmetry, which ultimately results in the increased efficiency of investments (Biddle et al., 2009).

IFRS establish and rank the qualitative characteristics required from financial information, grouping data into two categories: fundamental (relevance and faithful representation) and amplifying (comparability, verifiability, intelligibility and timeliness) (IASB, 2015). In this context, the timeliness of the financial information published by companies is defined by reference to the ability of the accounting income to expand its perimeter of recognition towards the size of the economic income (Lara \& Mora, 2004) respectively, to include potential gains and losses resulting from future cash flows generated by current operations (Ball \& Shivakumar, 2005).

The need to estimate the qualitative level of financial information, from the perspective of timeliness, has led to the development of econometric models focused on two main interpretative directions. Thus, Basu (1997) is a landmark for models developed on the relation between the accounting side of financial information and the perspective of data on the financial (mostly stock) market, by analysing the extent to which the evolution of indicators that reflect investors' decisions (in general, indicators concerning share profitability) correlates with earnings reported by economic entities. The evolving connection among information reported through financial statements, as a tool for the identification of transient elements (gains and potential losses) is captured in the models whose starting point is the deterministic relation proposed by Ball et al. (2000a).

The timeliness of published earnings is highly debated in the specialised literature, the latter attempting to cover the whole range of issues relevant to this topic. Thus, from the point of view of space and under the influence of the application of the International Financial Reporting Standards (IFRS,) studies have analysed the timeliness of earnings in relation to reporting entities from European countries (Dargenidou \& McLeay, 2010; Istrate, 2013; Chan et al., 2015), Latin America (Rodríguez García et al., 2017) and Romania, respectively (Dobre et al., 2015). The effects of the introduction of asset evaluation at fair value on the quality of reported results, including timeliness, in the North American region, is investigated by Kim et al. (2013). In order to deepen the analysis, researchers resorted to disjunctive factors as well, such as presence on a stock market (through the creation of groups of listed or unlisted companies), indebtedness, field of business operations, auditor's size or reputation, in research such as the one made by Ball 
and Shivakumar (2005), Coelho et al. (2017), their results reflecting the timeliness of published information under the action of established variables.

This paper analyses, in terms of timeliness, the quality level of the financial information published by the Romanian companies whose securities are accepted to be traded on the regulated section of the Bucharest Stock Exchange (BSE). Also, the study aims at assessing the symmetry of the actions of timely recognition of potential gains and losses (components of the economic income), as well as, in the case of the existence of an asymmetry, the identification of the sense of the temporary gap. The phenomenon is analysed in correlation with a number of disjunctive factors such as the specific features of the applied accounting rules (Romanian Accounting Standards-RAS; IFRS), the degree of indebtedness or the entities' field of operations.

Quantitative analysis performed through econometric models consecrated in the field reveals that the companies included in the study provide financial information that meets the qualitatively criterion assessed, respectively earnings timeliness. By deepening the analysis researchers have identified the existence of a timely recognition both in the case of unrealised gains and in the case of potential losses. Tests carried out at the level of the entire sample, an advance in relation to the inclusion of economic losses in the accounting income, compared to the recognition of economic gains (elements specific to the manifestation of conservatism). These findings confirm a series of results obtained by Dimitropoulos and Asteriou (2008) and Eriotis et al. (2009), respectively. The inclusion of disjunctive factors in the analysis has generated a number of particular results. In the case of companies with a normal level of indebtedness and which apply the IFRS, we found a timely recognition of economic gains and losses, similar to results identified by the Dargenidou and McLeay (2010), Dimitropoulos et al. (2013) and Rodríguez García et al. (2017) respectively, without the gap specific to conservatism. The involvement, as a disjunctive factor, of the field of activity has led to the conclusion that the qualitative variable does not have significant influences, which confirms the findings of Ball and Shivakumar (2005).

The paper is organised as follows: the first section highlights the main information landmarks concerning the phenomenon under investigation, in terms of the description of concepts and relations in which they are involved. It is precisely this perspective that grounds our working hypotheses. The second section describes our methodological approach, and specifies the population, sample, data and methods used for their processing. The third section presents our research results and their interpretation. The concluding section features the main results and the implications of our analyses, and it gives the limits of the study as well as directions for future research. 


\section{Literature review}

The fundamental objective of financial statements published by entities is to provide users with information that best meets their needs and which is a solid foundation in the conduct of the investment process. Although present in national and international accounting norms as desiderata of financial information reported by companies, the qualitative characteristics of financial information have been significant concerns in the specialised literature, following debates on this topic resulting in quantifying mechanisms.

\subsection{Qualitative perspectives of the information reported by quoted Romanian companies}

International and national regulators have carried out a comprehensive process to identify and systematise the main features that the information included in financial reports published by companies must include. In this respect, IFRS stipulate and rank the qualitative criteria that financial information must meet. Thus, in order to be useful, the information must first be relevant and give a faithful representation of transactions and events (fundamental qualitative features), as well as comparable, verifiable, intelligible and timely (amplifying characteristics) (IASB, 2015). This structure and hierarchy of the qualitative dimensions laid down in international standards have been taken over in most national regulations, where the IFRS are not applied as such.

Romanian accounting regulations have recorded over the last two decades an extensive process of adaptation to the conditions of an emerging economy, where economic events constantly change their characteristics, and to the specific accounting treatments provided by IFRS. The level of convergence between Romanian accounting standards and IFRS has steadily increased over the past decade, moving from specific accounting aspects, such as the treatment of tangible assets or leased assets, to a general degree of harmonization of around $80 \%$, currently registered (Albu \& Palarie, 2016).

In this evolutionary context, starting January 1,2012 , entities whose securities have been admitted to trading on the regulated market of the Bucharest Stock Exchange (BVB) must mandatory apply the IFRS. In Romania, a country that has used the continental accounting system in which accounting rules are enforced through codes of laws, the transposition of the international accounting regulations (IFRS) in the national legislation was carried out through the Order of the Minister of Public Finances (OMFP) no. 1286/2012 for the Approval of Accounting Regulations in line with IFRS applicable to companies whose securities are admitted to trading on a regulated market. This accounting norm was abrogated and replaced, for the same purpose of the adaptation of accounting treatments to 
the changes of international regulations and economic environment conditions, through OMFP no. 2844/2016 for the Approval of Accounting Regulations in line with IFRS.

For all other non-financial entities whose fundamental objective is to make profit, accounting registration is carried out according to RAS, implemented through OMFP no. 1.802/2014 for the Approval of the Accounting Regulations Concerning Individual Annual Financial Statements and Consolidated Annual Financial Statements, which largely recognises IFRS provisions, including those on the structure and hierarchy of the qualitative characteristics of financial information.

Relevant financial information is the information that can help its users in the decision-making process (OMFP 1802/2014). Information can make a difference in decision-making even if some users choose not to take advantage of this information or if they already know it from other sources (Toma, 2012). It has been estimated that financial-accounting information is relevant if it has predictive value, confirmation value or both value categories. Annual financial statements describe economic phenomena in words and figures. In order to provide a perfect faithful representation, a description must fulfil three conditions, namely: to be complete, neutral and error-free (Toma et al., 2015).

Considered a factor that enhances the usefulness of financial information in the decision-making process, comparability is the characteristic feature that allows comparisons to be made in time and space, so as to assess financial stance and performance. From a spatial perspective, the globalisation of financial markets identifies the need to harmonise accounting standards, since current and potential investors demand qualitative information that allows comparisons to be made between financial reports developed in different countries (Bryce et al., 2015). Nobes and Stadler (2015) note that verifiability refers to the existence of clear ways of explaining the accuracy of published information, which allows various informed and independent observers to reach a consensus. Intelligibility requires financial and accounting information to be presented in a clear and concise manner, to be classified and characterised (IASB, 2015). Financial reports are designed for users who have reasonable business knowledge. Timeliness requires information to be made available to decision-makers in a timely manner, and it can thus influence their decisions. Lack of timeliness is seen as a limitation of the information system (Gullberg, 2016).

Accounting information is a subject of constant improvement, but we must not forget that the image presented by an entity through financial statements depends on the professionalism and objectivity of the person(s) who builds this image, as well as on the correct perception of the message transmitted by accounts, by the users of accounting information. 


\subsection{Contribution of timeliness to the amplification of the quality of financial information}

The need to quantify the extent to which financial information observes the qualitative criteria required by accounting norms has led to the emergence of new conceptual terms in the literature. Thus, researchers in the field have introduced theoretical constructs that capture, within their explanatory area, the main characteristics of types of earnings and their components (Kamarudin \& Ismail, 2014).

The quantitative representation of timeliness is concerned with identifying the extent to which income and its components capture the information available at the time of publication of financial statements, under all aspects.

Ball and Shivakumar (2005) assert that the accounting income is a barometer for the appreciation of the reporting process in general because changes in the balance sheet structure generate effects in the profit or loss account. Ball et al. (2000a) define timeliness as the extent to which the accounting income of the current period incorporates the current economic income, estimated as a variation of the market value of shares, except for distributed dividends and the variation of invested capital. The economic income exceeds the accounting income in terms of its scope of recognition, by integrating gains and losses that are not registered in accounting data but that can be estimated. Timeliness is another property of accounting figures that expresses the availability of financial information to its users before losing the ability to influence investment decisions (Eriotis et al., 2009).

For Leventis and Weetman (2004), the timeliness of earnings reported by companies contributes to the analysts' better knowledge, determines the convergence of forecasts and facilitates the control of risk and benefits resulting from taking them.

\subsection{Dimensions of the timeliness of reported results}

Ball and Shivakumar (2005) note the fundamental asymmetry of accounting treatments in terms of the recognition of economic gains and losses. Economic losses are caused by the decrease in the present value of future cash flows generated by an investment. Timeliness implies that when a potential expected loss is detected, an element that aims at correcting the accounting value of assets should be recognised. Unlike this situation, the recognition of unrealised gains tends to be done in a non-timely manner (Ball et al., 2000b). 
That timely recognition of losses limits the ability of managers to manipulate results by concealing weak performance in order to gain their own or current shareholders' advantage (Chan et al., 2014) and discourages those investments for which the present value of cash flows is expected to be negative and it influences the cost of attracted credits (Ball \& Shivakumar, 2005). As a result, managers can give up unprofitable projects, thus mitigating economic losses (Srivastava et al., 2015).

The timeliness in recognising losses does not result from the deferral of the recognition of economic gains by comparison to the recognition of losses, nor does it induce an under-valuation of assets; it involves only the recognition of negative results in accounting registration in a timely manner (Roychowdhury, 2010).

Thus, specialised literature delimits the timely reporting of information from the asymmetric recognition of the components of the economic income, retaining, as a characteristic feature of conservatism, the existence of a gap between the time when economic losses are recognised, by comparison to the recognition of gains.

Basu (1997) defines the conservatism as the tendency of accounting to require a greater degree of verification of information for the recognition of economic gains (good news) in financial statements compared to economic losses (bad news).

Frequently debated, the concept of conservatism still stirs ample debates on the perspective of the representation of economic phenomena. Unconditional conservatism describes the phenomenon strictly from an accounting perspective, derived from the application of the prudence principle. Unlike this view, conditional conservatism significantly implies management decisions on the use of ways to integrate economic gains or losses in the accounting income (Chan et al., 2011). According to Dimitropoulos and Asteriou (2008), the timeliness of earnings and conservatism are indicators that estimate the efficiency of financial markets.

\subsection{Hypotheses development}

The quality of the reported results, appreciated through their timeliness, is a constant concern of researchers in the field, the certification of financial information contributing to the maturation of financial markets, respectively to the mitigation of uncertainties that characterise the investment process.

Estimating the level and analysing the timeliness of earnings in terms of an asymmetry between the moments in which losses and economic gains are recognised are the main dimensions of the studies conducted on the subject. To deepen the research, additional variables present in the space of the analysis are involved, that describe conditions in the economic environment at micro or macro level. 
After the analysis on the presence of timeliness and of conservatism at the level of published information by Greek listed companies, Dimitropoulos and Asteriou (2008) note the absence of timeliness in the recognition of earnings, as well as an increase in conservatism, and they express, at the same time, their reserves on the efficiency of the econometric models used in the case of the studied economic area. The results are confirmed by Eriotis et al. (2009), who identify a similar asymmetry in recognising predictable losses and gains, "bad news" is reported in a timely fashion, and "good news" is not included in the current accounting income. However, following an ex-post analysis, the authors note an increased persistence of the recognition of gains against the reporting of potential loss.

At the level of the European Union, Dargenidou and McLeay (2010) analyse the effect generated by the mandatory application of the International Financial Reporting Standards on the timeliness and the comparability of financial information. The results of this study show an increase in the timeliness of earnings, by the accounting recognition of financial market news (as a result of the inclusion of estimates of future gains in accounting registrations), as well as a significant increase in comparability. In the study conducted at European level, Istrate (2013) analyses the impact of the mandatory application of the IFRS on conservatism, by using the Gray index. Referencing information published by companies listed on Euronext markets (Amsterdam, Brussels, Lisbon, and Paris), the author identifies a decrease in conservatism in all European countries, in the case of financial statements drawn in accordance with the IFRS. The application of the IFRS by Latin American companies has generated a positive effect on the relevance and timeliness of financial information (Rodríguez García et al., 2017).

The impact of the introduction of the fair value valuation of assets as an exponent of the inclusion in accounting registrations of forecasts of future cash flows in the North American area is investigated by Kim et al. (2013). The authors note that, although this was a regulation that raised concerns about the recognition of certain unverifiable data, which opened the way for potential earnings management activities, the application of these provisions led to the mitigation of the asymmetry associated to the timeliness of earnings, respectively to the reduction of conservatism, which affected, nevertheless, the ability of the accounting income to reflect the entire size of the economic income.

Ball and Shivakumar (2005) undertook a comparative study of the quality of reported results, in terms of timeliness in recognising losses, at the level of public (listed) and private (unlisted) UK companies. Thus, they noted a lower level of the quality of information published by private companies, even though the two groups (private companies and public companies) draw financial statements according to the same accounting rules. The authors do not explain this gap through the failure of accounting regulations or audit rules, nor do they mention the need for stricter 
standards. They regard financial statements as economic goods whose quality depends on the demand on the specific market, the information published by listed entities being in this case subject to a higher demand from its users. Following the testing of the effect of control variables, such as indebtedness, field of economic operations, size, or auditor's reputation, the study results were not affected by changes. By applying the same approach to the specific features of Brazilian firms, Coelho et al. (2017) reach different results, identifying a similar level of information quality reported by public and private entities. The authors explain the situation by referring to the conditions of the investigated economic area, namely its accounting system based on codes of laws and weak investor protection.

The timeliness of loss recognition and the influence of factors from the economic environment or of organisational factors on it are analysed in the European context by Chan et al (2015). In this sense, the mandatory application of the IFRS contributes to increasing the extent to which probable losses are recognised in the accounting income, in countries with a high credit cost and whose financial system relies on banks. The direction of the correlation is also preserved in case of the use as control variables of factors such as: assets return, earnings volatility, quality of accruals, activity field, degree of indebtedness or even country characteristics (public debt).

In the Romanian context, Dobre et al. (2015) analyse the timeliness of the recognition of losses in the financial statements of companies listed on the BVB. From this perspective, the authors find an improved quality of financial information, which parallels the mandatory application of the IFRS beginning with the financial year 2012 .

Starting from the conceptual milestones and the results of the studies identified in the literature, we propose the following working hypotheses for validation:

H1: The financial information reported by listed Romanian entities includes to a significant extent components of the economic income.

H2: There is and one can estimate an asymmetry in the timeliness of the recognition of the components of the economic income (losses vs. earnings) at the level of the financial information published by companies listed on BVB.

H3: A series of factors such as the specificity of accounting norms (RAS, IFRS), indebtedness, and field of activity significantly influence the level of the timeliness of results reported by Romanian companies listed on BVB. 


\section{Methodological approach}

While testing the proposed working hypotheses, this paper aims to analyse the quality of the financial information reported by the listed Romanian companies, by estimating the timeliness of earnings. In order to know the features of the process of including economic gains and losses in the accounting income, the study aims to estimate the symmetry of recognition actions and, in case such an asymmetry exists, to identify the sense of the time gap. Also, the inclusion in our analysis of control factors such as the specificity of accounting rules (RAS, IFRS), the degree of indebtedness, the field of activity, provides sequential details on the timeliness of reported earnings in the Romanian economic context, with explanations of the dimensions of the mentioned phenomenon. This can lead to the adoption of solutions for the improvement of the quality of financial information.

\subsection{Data, population and sample}

Companies listed on the regulated BVB section represent our analyses population, the selected sample including only non-financial entities. The data was collected from the financial statements published by the selected companies, available on the BVB website or on their own sites, and they cover 6 fiscal years - 2010-2015. Due to the inherent difficulties related to the mandatory preparation of financial statements under the IFRS, starting with the financial year 2012, the information specific to the transition period (the financial year 2012) was not included in the analysis. Thus, the 62 companies that constitute our analyzed sample, grouped according to the specificity of their field of operations (constructions, industry, trade and services), have allowed us to make 310 observations on their financial and non-financial characteristics.

\subsection{Econometric models used to estimate the timeliness of earnings}

The quantitative representation of the timeliness of reported results requires data analysis using econometric models based on multiple regression analysis.

The quantification of the relevance of financial information has been a concern for many researchers in the field. The model proposed by Basu (1997), whose relation is presented in equation no. 1 below, is representative for many economic areas and at the same time, it represents the foundation of the development of other relations to estimate the timeliness of earnings:

where:

$$
N I_{t}=\alpha_{0}+\alpha_{1} D K_{t}+\alpha_{2} K_{t}+\alpha_{3} K_{t} \times D K_{t}+\varepsilon_{t}
$$

$\mathrm{NI}_{\mathrm{t}}=$ net income per share for year $\mathrm{t}$, denominated with year $\mathrm{t}-1$ share price; 
$K_{t}=\frac{P_{t}-P_{t-1}+D_{t}}{P_{t-1}}=$ share return at the end of year $\mathrm{t}$ (economic income);

$\mathrm{P}_{\mathrm{t}}$ şi $\mathrm{P}_{\mathrm{t}-1}=$ stock exchange rate mid-year $\mathrm{t}+1$, respectively year $\mathrm{t}$;

$\mathrm{D}_{\mathrm{t}}=$ dividend per share for year $\mathrm{t}$;

$D K_{t}=$ dummy variable corresponding to the share's return, used for the purpose of separating economic losses and gains, whose value is 1 if the share's return is negative and 0 when the latter is positive;

$\alpha_{2}=$ reflects the sensitivity of net income to the evolution of economic income; $\alpha_{2}>0$ shows an increase in the accounting recognition of economic gains;

$\alpha_{3}=$ signals the existence of a gap (advance) in the recognition of economic losses compared to potential gains, thus expressing a manifestation of conservatism;

$\alpha_{2}$ and $\left(\alpha_{2+} \alpha_{3}\right)=$ describe the global sensitivity of the net income to the variation of the entity's market value.

Starting from the model of Basu (1997), Ball and Shivakumar (2005) develop a new model for estimating the degree of timeliness of reported results - equation no. 2. The authors support the efficiency of using the variation of net income to explain the extent to which economic losses and gains are recognised.

where:

$$
\Delta N I_{t}=\beta_{0}+\beta_{1} D \Delta N I_{t-1}+\beta_{2} \Delta N I_{t-1}+\beta_{3} \Delta N I_{t-1} \times D \Delta N I_{t-1}+\varepsilon_{t}
$$

$\Delta \mathrm{NI}_{\mathrm{t}}=$ the variation of the net income in year $\mathrm{t}$ compared to $\mathrm{t}-1$, denominated with the total net assets from the beginning of year $\mathrm{t}-1$;

$D \Delta N I_{t-1}=$ the dummy variable corresponding to the variation of the net income is 1 if the variation of the net income from the previous year is negative and 0 , when the latter is positive;

$\beta_{2}=$ reflects the sensitivity of the current net income to the previous variation of the net income; $\beta_{2}=0$, the result is persistent (it shows a lack of recognition of the provisioned components of the economic income). Due to the transience of the recognition of economic losses and gains, $\beta_{2}<0$ shows an increase of their inclusion in the net income, whereas $\left(\beta_{2+} \beta_{3}\right)<0$ signifies an increase in the presence in information reported in financial statements of probable economic losses;

$\beta_{3}=$ signals the existence of a gap in the recognition of economic losses compared to potential gains; $\beta_{3}<0$ signals the presence of conservatism.

The ability of the net income to reflect both dimensions of the economic income (predicted gains and losses) and the timeliness of reported results are reflected by the size of the determination ratio $\left(\mathrm{R}^{2}\right)$, for both models.

Data processing was conducted using GLM (general linear model) to quantify the influences of the control factors considered in the study, namely the specificity of 
accounting rules (RAS, IFRS), the degree of indebtedness and the field of economic operations (constructions, industry, trade and services).

Equations no. 3, 4, 5 and 6 reflect the relationships derived from Basu (1997) model, resulting from the inclusion of the control variables.

$$
\begin{gathered}
N I_{t}=\alpha_{0}+\alpha_{1} D K_{t}+\alpha_{2} K_{t}+\alpha_{3} K_{t} \times D K_{t}+\alpha_{4} \mathrm{Vsim}+\varepsilon_{t} \\
N I_{t}=\alpha_{0}+\alpha_{1} D K_{t}+\alpha_{2} K_{t}+\alpha_{3} K_{t} \times D K_{t}+\alpha_{4}\left(K_{t} \times D K_{t} \times F L_{t}\right)+\varepsilon_{t} \\
N I_{t}=\alpha_{0}+\alpha_{1} D K_{t}+\alpha_{2} K_{t}+\alpha_{3} K_{t} \times D K_{t}+\alpha_{4}\left(K t \times D K_{t} \times N o r m_{t}\right)+\varepsilon_{t} \\
N I_{t}=\alpha_{0}+\alpha_{1} D K_{t}+\alpha_{2} K_{t}+\alpha_{3} K_{t} \times D K_{t}+\alpha_{4}\left(K t \times D K_{t} \times \text { Kom }_{t}\right)+\varepsilon_{t}
\end{gathered}
$$

The same approach applied to Ball and Shivakumar (2005) model generates the relationships expressed in equations no. 7, 8, 9, and 10 .

$$
\Delta N I_{t}=\beta_{0}+\beta_{1} D \Delta N I_{t-1}+\beta_{2} \Delta N I_{t-1}+\beta_{3} \Delta N I_{t-1} \times D \Delta N I_{t-1}+\beta_{4} \mathrm{Vsim}+\varepsilon_{t}
$$

$\Delta N I_{t}=\beta_{0}+\beta_{1} D \Delta N I_{t-1}+\beta_{2} \Delta N I_{t-1}+\beta_{3} \Delta N I_{t-1} \times D \Delta N I_{t-1}+\beta_{4}\left(\Delta \mathrm{NI}_{\mathrm{t}-1} \times \mathrm{D} \Delta \mathrm{NI}_{\mathrm{t}-1} \times \mathrm{FL}_{\mathrm{t}}\right)$

$+\varepsilon_{t}$

$\Delta N I_{t}=\beta_{0}+\beta_{1} D \Delta N I_{t-1}+\beta_{2} \Delta N I_{t-1}+\beta_{3} \Delta N I_{t-1} \times D \Delta N I_{t-1}+\beta_{4}\left(\Delta \mathrm{NI}_{\mathrm{t}-1} \times \mathrm{D} \Delta \mathrm{NI}_{\mathrm{t}-1} \times\right.$

$\left.\operatorname{Norm}_{\mathrm{t}}\right)+\varepsilon_{t}$

$\Delta N I_{t}=\beta_{0}+\beta_{1} D \Delta N I_{t-1}+\beta_{2} \Delta N I_{t-1}+\beta_{3} \Delta N I_{t-1} \times D \Delta N I_{t-1}+\beta_{4}\left(\Delta \mathrm{NI}_{\mathrm{t}-1} \times \mathrm{D} \Delta \mathrm{NI}_{\mathrm{t}-1} \times\right.$

$\left.\operatorname{Dom}_{\mathrm{t}}\right)+\varepsilon_{t}$

Where:

Vsim - the variable that synthesises the simultaneous action of the qualitative factors (indebtedness and specific features of the accounting rules). For the Basu model (1997) Vsim $=\mathrm{K}_{\mathrm{t}} \times \mathrm{DK}_{\mathrm{t}} \times \mathrm{FL}_{\mathrm{t}} \times$ Norm $_{\mathrm{t}}$, and for the Ball and Shivakumar (2005) model, $\mathrm{Vsim}=\Delta \mathrm{NI}_{\mathrm{t}-1} \times \mathrm{D} \Delta \mathrm{NI}_{\mathrm{t}-1} \times \mathrm{LF}_{\mathrm{t}} \times \mathrm{Norm}_{\mathrm{t}}$

Dom= qualitative variable (dummy) takes value 1 if the entity belongs to the industrial field and 0 for the other cases (services and trade, or constructions, respectively)

$\mathrm{FL}=$ financial leverage, dummy variable, takes value 1 if the company is normally indebted and 0 if the company is over-indebted

Norm=dummy variable, takes value 1 if the company apply the IFRS and 0 if the company apply the RAS

The degree of indebtedness is appreciated by the size of the financial leverage - FL $=$ financial liabilities / equity. Thus, if FL $>2$, the company is over-indebted, and if $\mathrm{FL}<2$ the company is normally indebted. The data was processed using the SPSS 20.0 software.

\section{Discussion of results}

The characterisation of the economic environment in which the analysis is conducted, through the perspective of factors involved in our study, contributes to the identification and assessment of the relations of influence under investigation. Based on the data rendered synthetically in Table 1, one can notice both the mean size of variables as well as the indicators of the concentration of the data series, at 
intervals or around the mean value. The data also showcase an evolving dimension of the presented information. Thus, the size of the net income, the degree of indebtedness and the return of shares are captured at the level of the whole sample and sequentially, according to the applied accounting rules (RAS or IFRS), implicitly along time intervals characterised by their incidence (2010 and 2011 RAS, 2013, 2014 and 2015-IFRS).

Table 1. Descriptive statistics of the analysed variables

\begin{tabular}{|c|c|c|c|c|c|c|c|c|c|c|}
\hline \multirow[t]{2}{*}{ Elements } & \multirow{2}{*}{$\begin{array}{l}\begin{array}{l}\text { No } \\
\text { obs. }\end{array} \\
\mathrm{N}\end{array}$} & \multicolumn{3}{|c|}{ Total sample } & \multicolumn{3}{|c|}{ RAS period } & \multicolumn{3}{|c|}{ IFR period } \\
\hline & & Mean & $\begin{array}{l}\text { Std } \\
\text { dev }\end{array}$ & $\begin{array}{l}\mathrm{Me} \\
\text { dian }\end{array}$ & Mean & $\begin{array}{l}\text { Std } \\
\text { dev }\end{array}$ & $\begin{array}{l}\mathrm{Me} \\
\text { dian }\end{array}$ & Mean & $\begin{array}{l}\text { Std } \\
\text { dev }\end{array}$ & $\begin{array}{l}\mathrm{Me} \\
\text { dian }\end{array}$ \\
\hline NI & 310 & -0.063 & 0.53 & 0.033 & -0.049 & 0,49 & 0.035 & -0.075 & 0.63 & 0.042 \\
\hline $\mathbf{K}$ & 310 & 0.044 & 0.53 & 0.043 & -0.015 & 0.36 & 0.05 & 0.105 & 0.73 & 0.025 \\
\hline FL & 310 & 0.950 & 2.83 & 0.465 & 0.968 & 2.30 & 0.461 & 0.931 & 3.30 & 0.468 \\
\hline
\end{tabular}

Source: own processing in SPSS 20.0.

At the level of the whole sample, the negative mean dimension $(-0,063)$ of net income per share reflects a low performance of Romanian companies. The positive value of the median (0.033) reveals that fewer than $50 \%$ of the entities register losses, but their volume exceeds the value of positive earnings. The indebtedness ratio (0.950) shows a reduced dependence of entities on borrowed resources, the median value $(0.465)$ confirming that $50 \%$ of the subjects have a low financial leverage. The return of shares records a positive value (0.044) with a balanced distribution around the mean (median of 0.043).

Also, a significant dispersion of earnings around the mean is identified, which reflects a wide variation in the performance of listed companies, both at the level of the sample and in the case of clusters formed according to the applied accounting rules. At the same time, there is an increased return of shares during IFRS versus RAS ( $\left.\mathrm{K}_{\mathrm{IFRS}}=0,105>\mathrm{K}_{\mathrm{RAS}}=-0,015\right)$, paralleled by a reduction in the indebtedness degree $\left(\mathrm{FL}_{\mathrm{IFRS}}=0,931<\mathrm{FL}_{\mathrm{RAS}}=0,968\right)$, but in the context of the reduction of net income (on average, by 0.026). This may be due to the maturation of the Romanian stock market and to the existence of growth prospects for the economy and the financial market.

Under the circumstances, the timeliness of reported earnings asserts its role as a connector of financial and non-financial information that grounds investment decisions.

The simultaneous application of the two models for the estimation of the timeliness of financial information aims at grounding drawn conclusions, as well as at identifying their relevance in the case of the Romanian stock market. 
Thus, Table 2 presents the results obtained via the proposed models, by Basu (1997) and Ball and Shivakumar (2005). The regression coefficients of the above mentioned models were estimated, as well as those resulting from the introduction in the analysis of the simultaneous action of independent variables such as the financial leverage (transformed into the qualitative variable) and the specificity of the applied accounting rules.

Table 2. Estimates of regression coefficients after the application of GLM

\begin{tabular}{|c|c|c|c|c|c|c|c|}
\hline \multicolumn{8}{|c|}{$N I_{t}=\alpha_{0}+\alpha_{1} D K_{t}+\alpha_{2} K_{t}+\alpha_{3} K_{t} \times D K_{t}+\varepsilon_{t}$} \\
\hline $\begin{array}{l}\text { Dependent } \\
\text { variable }\end{array}$ & Intercept & $\alpha_{1} D K$ & $\alpha_{2} \mathrm{~K}$ & $\alpha_{3} K_{t} * D K_{t}$ & $\alpha_{4} \mathrm{Vsim}$ & $\mathrm{R}^{2}$ & Sig. \\
\hline$N I_{t}$ & 0.035 & -0.166 & -0.086 & 0.168 & & 0.027 & 0,101 \\
\hline$N I_{t}$ & 0.035 & -0.176 & -0.086 & 0.026 & 0.389 & 0.037 & 0.072 \\
\hline \multicolumn{8}{|c|}{$\Delta N I_{t}=\beta_{0}+\beta_{1} D \Delta N I_{t-1}+\beta_{2} \Delta N I_{t-1}+\beta_{3} \Delta N I_{t-1} \times D \Delta N I_{t-1}+\varepsilon$} \\
\hline$\Delta N I_{t}$ & Intercept & $\begin{array}{l}B_{I} D \\
\Delta N I_{t-1}\end{array}$ & $B_{2} \Delta N I_{t-1}$ & $\begin{array}{l}B_{3} \Delta N I_{t-1} \\
D \Delta N I_{t-1}\end{array}$ & $\beta_{4} \mathrm{Vsim}$ & & \\
\hline$\Delta N I_{t}$ & 0.037 & -0.073 & -0.418 & -0.176 & & 0.373 & 0.000 \\
\hline$\Delta N I_{t}$ & 0.037 & -0.074 & -0.418 & -0.185 & 0.322 & 0.376 & 0.000 \\
\hline
\end{tabular}

Vsim - the variable that synthesises the simultaneous action of the qualitative factors (indebtedness and specific features of the accounting rules). For the Basu model (1997) Vsim $=\mathrm{K}_{\mathrm{t}} \times \mathrm{DK}_{\mathrm{t}} \times \mathrm{FL}_{\mathrm{t}} \times \operatorname{Norm}_{\mathrm{t}}$, and for the Ball and Shivakumar (2005) model, Vsim $=$ $\Delta \mathrm{NI}_{\mathrm{t}-1} \times \mathrm{D} \Delta \mathrm{NI}_{\mathrm{t}-1} \times \mathrm{LF}_{\mathrm{t}} \times \mathrm{Norm}_{\mathrm{t}} . \alpha_{4}$ and $\beta_{4}$ represents the regression coefficients attached to the Vsim variable, in the case of the introduction of the variable in the model.

Source: own processing in SPSS 20.0.

Applied in the Romanian context, Basu (1997) offers a series of less conclusive data. Starting from a low significance degree of the model $($ Sig. $=0.101)$, the model explains the variation of net income to a low extent, through influences generated by independent variables as an expression of information from the market $\left(R_{2}=0.027\right)$. In this context, the timeliness of earnings reported by listed Romanian companies would be at a low level. Following the analysis of the size of regression coefficients attached to the independent variables introduced in the model, the conclusions drawn are limited, both because of their low statistical significance and because of their size. Thus, $\alpha_{2}=-0.085$ shows a weak influence of shares return on net income, respectively a low recognition of potential gains or losses, while $\alpha_{3}=0.168$ confirms (by size) the existence of a small gap between the recognition of economic gains and losses within the accounting income. In fact, the opposite sign of the two coefficients cancels their influence on the result, thus highlighting the poor connection between the two dimensions of the information (accounting and market). This contradicts a series of results from studies such as Jaba et al. (2016) and Carp (2016), which argued for the opposite. The inclusion of qualitative factors in the analysis increases the explanatory capacity of the model $\left(\mathrm{R}^{2}=0.037\right)$ and shows that for entities with normal indebtedness levels and during the period when they apply the IFRS, there is an increase in the recognition of the 
unrealised components of the economic income within the accounting income. This increases the timeliness of the published information, which confirms a series of results obtained by Dargenidou and McLeay (2010), Dobre et al. (2015) and Rodríguez García et al. (2017), respectively.

In our opinion, the Ball and Shivakumar (2005) model corresponds to the specific conditions of the Romanian stock market. Based on the information derived from the evolution of previous net income, the model avoids the implications of share price variations which, under the circumstances of an emerging (immature) stock market such as the Romanian one, does not reflect only the influences of rationally grounded decisions but mainly follows the path traced by a series of psychological factors. From a statistical point of view, the model is significant and one can argue that by assuming a 5\% risk, it best explains the link between actual data.

The value recorded by the determination ratio $\mathrm{R}^{2}(0.373)$ shows that, in the case of the information published by the listed Romanian companies, the qualitative level is representative from the point of view of timeliness, global earnings reported in the previous year providing a $37.3 \%$ explanation of the variation of current earnings. This results validate our first research hypothesis.

The timeliness of reported results is revealed sequentially through the values and signs of regression coefficients specific to the variables introduced in the econometric models tested. Thus, $\beta_{2}=-0.418$ identifies, via its magnitude and sign, the recognition of potential gains in the accounting income. The conclusion is explained by the transience of the components of the economic income; an increase in foreseeable gains recognised in the previous period leads to a reduction in the current accounting income.

The timely recognition of losses is confirmed by the result of the cumulating of the

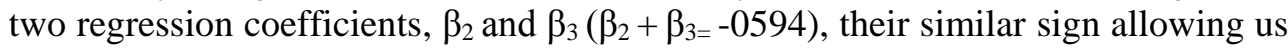
to conclude that the accounting income retains probable economic losses to a significant extent. The analysis of the possible gap in the timeliness of the recognition of gains vs that of foreseeable losses is reflected by the magnitude and sign of the $\alpha_{3}$ coefficient. In the present situation, $\beta_{3=}-0.176\left(\beta_{3}<0\right)$ shows the presence of conservatism at the level of information published by listed Romanian companies, losses being recognised in a more heightened manner than economic gains, fact which validate our second research hypothesis. In our opinion, this situation derives from the continental character of the Romanian accounting system, in which the principle of prudence is fully manifest. The results confirm a series of conclusions formulated, with reference to listed Greek companies, by Dimitropoulos and Asteriou (2008), and by Eriotis et al. (2009), respectively.

By including qualitative variables in the model, the specificity of accounting rules and the degree of indebtedness, the relevance of the conclusion concerning the 
presence of conservatism on the Romanian stock market diminishes. Companies that apply the IFRS and have a normal level of indebtedness publish more timely information, $\beta_{2}=-418\left(\beta_{2}<0\right)$ and $\beta_{2}+\beta_{4=}-0.096\left(\beta_{2}+\beta_{4}<0\right)$, similar to Dargenidou and McLeay (2010), Dimitropoulos et al. (2013) and Rodríguez García et al. (2017), respectively; yet, in the case of Romania, it is characterised by low conservatism. The $\beta_{4}=0.322\left(\beta_{4}>0\right)$ coefficient signifies the absence of the gap between the timely recognition of the two unrealised components of the economic income, and this conclusion can be explained by the nature of the international rules which provide for a number of options regarding accounting treatment and the conditions for the recognition of the effect of future cash flows in the accounting income. This enables the extension of the informative perimeter of the accounting income towards the size of the economic income.

In order to deepen the analysis of the phenomenon, information on qualitative variables (the specific features of accounting norms, the degree of indebtedness, the field of activity) were alternatively introduced in the selected models, and the results of the applied tests are presented in Table 3.

Table 3. Parameters of regression equations, with the representation of the effect of qualitative variables

\begin{tabular}{|c|c|c|c|c|c|c|c|}
\hline \multicolumn{4}{|c|}{$\begin{array}{l}N I_{t}=\alpha_{0}+\alpha_{1} D K_{t}+\alpha_{2} K_{t}+\alpha_{3} K_{t} \times D K_{t}+ \\
\varepsilon_{t}\end{array}$} & \multicolumn{4}{|c|}{$\begin{array}{l}\Delta N I_{t}=\beta_{0}+\beta_{1} D \Delta N I_{t-1}+\beta_{2} \Delta N I_{t-1}+\beta_{3} \Delta N I_{t-1} \times \\
D \Delta N I_{t-1}+\varepsilon\end{array}$} \\
\hline $\begin{array}{l}\text { Independent } \\
\text { Variables }\end{array}$ & $\mathrm{P}_{1}$ & $\mathrm{P}_{2}$ & $\mathrm{P}_{3}$ & $\mathrm{P}_{1}$ & $\mathrm{P}_{2}$ & $\mathrm{P}_{3}$ & $\begin{array}{r}\text { Independent } \\
\text { Variables }\end{array}$ \\
\hline Intercept & 0.035 & 0.035 & 0.035 & 0.037 & 0.037 & 0.037 & Intercept \\
\hline$D K$ & $-\overline{0} 183$ & $-\overline{0.170}$ & $-\overline{0} 165$ & $\overline{0}-074$ & $\overline{0}-074$ & & $D \Delta N I_{t-1}$ \\
\hline $\mathbf{K}$ & $-\overline{0}$ & $-\overline{0}$ & $\overline{-}-086$ & $-\overline{0.418}$ & $\overline{0}-418$ & $-\overline{0.418}$ & $\Delta N I_{t-1}$ \\
\hline$K_{t} \times D K_{t}$ & $-\overline{0}-024$ & 0.299 & 0.477 & $-\overline{0}(185$ & $-\overline{0}-960$ & 1.059 & $\Delta N I_{t-1} \times D \Delta N I_{t-1}$ \\
\hline $\begin{array}{l}K_{t} \times D K_{t} \times F L_{t} \\
K_{t} \times D K_{t} \times\end{array}$ & 0.682 & - & & 0.556 & 0.624 & & $\begin{array}{r}\Delta N I_{t-1} \times D \Delta N I_{t-1} \times F L_{t} \\
\Delta N I_{t-1} \times D \Delta N I_{t-1} \times\end{array}$ \\
\hline $\begin{array}{l}\text { Norm }_{t} \\
K_{t} \times D K_{t} \times\end{array}$ & & 0.107 & - & & & - & $\begin{array}{r}\text { Normt } \\
\Delta N I_{t-1} \times D \Delta N I_{t-1} \times\end{array}$ \\
\hline $\operatorname{Dom}_{t}$ & & & 0.227 & & & 0.739 & Dom \\
\hline $\mathbf{R}^{2}$ & 0.041 & 0.027 & 0.030 & 0.376 & 0.405 & 0.426 & $\mathbf{R}^{2}$ \\
\hline Sig. & 0.049 & 0.177 & 0.136 & 0.000 & 0.000 & 0.000 & Sig. \\
\hline
\end{tabular}

Pi- dependent variable (predictor) $\left(N I_{t}, \Delta N I_{t}\right.$, respectively) in the models which use qualitative factors alternatively. The qualitative variable Dom takes value 1 if the entity belongs to the industrial field and 0 for the other cases (services and trade, or constructions, respectively).

Source: own processing in SPSS 20.0. 
Under the influence of qualitative variables relevant for the application of Basu (1997) and Ball and Shivakumar (2005) models in the Romanian economic area, the results at this level are preserved, and they are in line with those identified in previous analyses. In the case of all tested situations, the Basu model (1997) has a minimal significance $\left(\operatorname{Sig}_{\mathrm{P} 1}=0.049 ; \mathrm{Sig}_{\mathrm{P} 2}=0.177 ; \mathrm{Sig}_{\mathrm{P} 3}=0.136\right.$ ), and a reduced explanatory capacity $\left(\mathrm{R}_{\mathrm{P} 1}^{2}=0,041 ; \mathrm{R}_{\mathrm{P} 2}^{2}=0,027 \mathrm{R}_{\mathrm{P} 3}^{2}=0,030\right)$. Unlike it, the Ball and Shivakumar (2005) model presents the interactions between the factors introduced in the model to a high extent $\left(\mathrm{R}_{\mathrm{P} 1}^{2}=0,375 ; \mathrm{R}_{\mathrm{P} 2}^{2}=0,405 \mathrm{R}_{\mathrm{P} 3}^{2}=0,426\right)$ and registers a representative degree of significance for all the proposed variants $\left(\mathrm{Sig}_{\mathrm{P} 1 ; \mathrm{P} ; \mathrm{P} 3}=0.000\right)$. For this reason, results obtained via Basu (1997) were considered inconclusive, which corresponds to certain inconsistencies noted by Dimitropoulos and Asteriou (2008) in their study of the timeliness of reported earnings, conducted on information published by listed Greek companies.

Information derived from testing the Ball and Shivakumar (2005) model provides relevant details on the timeliness of reported results, analysed sequentially under the influence of disjunctive factors. Thus, in the case of all model variants, the negative sign of the regression coefficient attached to the $\Delta \mathrm{NI}_{\mathrm{t}-1}\left(\beta_{2}\right)$ variable indicates the recognition of potential gains within the net income reported by the Romanian companies listed on BVB $\left(\beta_{2 \mathrm{P} 1 ; \mathrm{P} 2 ; \mathrm{P} 3}=-0,418\right)$. The timely reporting of losses is identified in the case of two of the three models, a conclusion supported by the negative sum of the $\beta_{2}$ and $\beta_{2}$ coefficients $\left(\beta_{2 \mathrm{P} 1}+\beta_{2 \mathrm{P} 1}=-0,603 ; \beta_{2 \mathrm{P} 2}+\beta_{2 \mathrm{P} 2}=-\right.$ 1.378). Also, in the case of the two models, the results concerning the influence of accounting rules and the degree of indebtedness remain convergent with conclusions drawn from testing the combined models. With reference to the financial information published by normally indebted companies and those that apply the IFRS, the presence of conservatism is not identified, which is expressed by positive values of $\beta_{4}$ coefficients $\left(\beta_{4 \mathrm{P} 1}=0.556 ; \beta_{4 \mathrm{P} 2}=0.624\right)$, respectively the existence of a gap in the timely recognition of losses compared to economic gains. Thus, we have reached conclusions similar to those outlined by Ball and Shivakumar (2005), according to whom the influence of the field of activity and the degree of indebtedness have a minimal significance in estimating the timeliness of reported results. The influence of the field of activity reveals, however, the existence of an advance in the timely recognition of losses in relation to unrealized gains $(\beta 4=-0.739)$, but only if companies operate in industry. By means of these conclusions, our third research hypothesis is validated.

The multi-criterial support of the obtained results was also achieved by checking the linearity of the model, by eliminating the effects of random connections between features associated with the analysed subjects; this was done by introducing, as a procedure, the fix effects control in the models tested in GLM. Our in-depth analysis and comparative results on the influence of this process are summarized in the tables presented as appendices (Appendix A, Appendix B, Appendix C, Appendix D). They highlight an increase in the explanatory capacity 
of econometric models. The relevance of using the two models, Basu (1997) and Ball and Shivakumar (2005), for the analysis of the timeliness of earnings reported by the listed Romanian companies, corresponds to that identified by classical regression analysis. In our opinion, only the Ball and Shivakumar (2005) model provides useful information in the Romanian context.

\section{Conclusions}

The assessment of the quality of accounting information, from the perspective of the timeliness of reported earnings, is a useful approach, with a significant resonance for the correct and full information addressed to investors present on stock markets. Their decisions suppose the analysis of a large set of both financial and non-financial data, which express the past, the present, and the prospects of operations conducted by economic entities. From this point of view, the ability of the accounting income to include elements regarding the nature of future (unrealized) cash flows generated by the entity's current operations enhances the usefulness of the information disclosed through financial statements and it also contributes to the limitation of uncertainties associated with the decision-making process.

By testing our working hypotheses, this article analyses the timeliness of the results reported by Romanian entities listed on the Bucharest Stock Exchange, with a focus on the evaluation of this qualitative characteristic feature by estimating the extent to which they are recognized in financial statements of predictable earnings and losses (components of the economic income). In this article, we have envisioned the global recognition of the potential components of earnings, the existence of a possible asymmetry in connection with the inclusion of economic losses and gains in the net income, as well as the potential advance in the recognition of probable losses, as an indicator of the presence of conservatism.

Our working hypotheses were tested via the econometric models established in the literature, Basu (1997) and Ball and Shivakumar (2005), the results obtained showing that in the Romanian context, only the information provided by Ball and Shivakumar (2005) can be considered relevant, a situation found by Dimitropoulos and Asteriou (2008) in their study on Greek companies.

Thus, following the validation of the three working hypotheses in the context of the Romanian stock market, financial statements provide timely financial information with a representative degree of significance. Deepening the analysis has made it possible to identify a timely recognition for both unrealized gains and potential losses as a result of the testing of the general model and an advance in the inclusion of economic losses in the accounting result compared to the recognition of economic gains. This confirms a series of results obtained by Dimitropoulos and Asteriou (2008), respectively Eriotis et al. (2009). The inclusion of controlled variables in the model such as the specificity of applied accounting rules, the 
degree of indebtedness and the field of activity has generated a number of particular results. In the case of normally indebted companies that apply the IFRS, a timely recognition of economic gains and losses was noted, similar to the results identified by Dargenidou and McLeay (2010), Dimitropoulos et al. (2013) and Rodríguez García et al. (2017), respectively, without the gap specific to conservatism. The involvement, as a disjunctive factor, of the field of activity, led to the conclusion that the qualitative variable has not had significant influences, which confirms the conclusions of Ball and Shivakumar (2005). It is only in the case of entities operating in the industrial field that there is a gap between the moments of the recognition of the two components of the economic income, potential losses exceeding unrealized gains from this point of view.

Our study complements the research field on the quality of financial information reported by Romanian companies, focusing on a less analyzed segment, the timeliness of earnings. This approach highlights both the role of tools for measuring the quality of financial information and the need to carry out more complex studies on this field.

The limits of the study consist in the small size of the sample and the number of observations, as well as the short period of time considered in the analysis (only five financial years). Also, the low number of control factors is an element that decreases the scope and depth of the study. The elimination of these restrictions constitutes the main future directions of research; pursuing them supposes the involvement of data specific to other stock markets in the research, in order to carry out comparative international analyses.

\section{References}

Albu, N. \& Palarie, I. (2016) "Convergence of Romanian accounting regulations with IFRS. A longitudinal analysis", Audit Financiar, vol. XIV, no. 6(138): 634-641

Ball, R. \& Shivakumar, L. (2005) "Earnings quality in UK private firms: comparative loss recognition timeliness", Journal of Accounting and Economics, vol. 39, no. 1: 83-128

Ball, R., Kothari, S. P. \& Robin, A. (2000a) "The effect of international institutional factors on properties of accounting earnings", Journal of Accounting and Economics, vol. 29, no. 1: 1-51

Ball, R., Robin, A. \& Wu, J. S. (2000b) "Accounting standards, the institutional environment and issuer incentives: Effect on timely loss recognition in China", Asia-Pacific Journal of Accounting \& Economics, vol. 7, no. 2: 71-96

Basu, S. (1997) "The conservatism principle and the asymmetric timeliness of earnings", Journal of Accounting and Economics, vol. 24, no. 1: 3-37 
Biddle, G. C., Hilary, G. \& Verdi, R. S. (2009) "How does financial reporting quality relate to investment efficiency?", Journal of Accounting and Economics, vol. 48, no. 2: 112-131

Bryce, M., Ali, M. J. \& Mather, P. R. (2015) “Accounting quality in the pre-/postIFRS adoption periods and the impact on audit committee effectivenessEvidence from Australia", Pacific-Basin Finance Journal, vol. 35: 163-181

Carp, M. (2016) "Empirical study regarding the influence of the quality of financial information on the value of listed companies", Audit Financiar, vol. 1, no. $133: 78-87$

Chan, L. C., Lee, E., Petaibanlue, J. \& Zeng, C. (2014) "Re-examining the relationship between PIN and timely loss recognition", Applied Financial Economics, vol. 24, no. 23: 1479-1489

Chan, A. L. C., Lin, S. W. \& Strong, N. (2011) "Earnings components and the asymmetric timeliness of earnings: the case of FRS 3 in the UK", Accounting and Business Research, vol. 41, no. 4: 393-410

Chan, A. L. C., Hsu, A. W. H. \& Lee, E. (2015) "Mandatory adoption of IFRS and timely loss recognition across Europe: The effect of corporate finance incentives", International Review of Financial Analysis, vol. 38: 70-82

Coelho, A. C., Galdi, F. C. \& Lopes, A. B. (2017) "Determinants of asymmetric loss recognition timeliness in public and private firms in Brazil", Emerging Markets Review, vol. 31: 65-79

Dargenidou, C. \& McLeay, S. (2010) "The impact of introducing estimates of the future on international comparability in earnings expectations", European Accounting Review, vol. 19, no. 3: 511-534

Dimitropoulos, P.E. \& Asteriou, D. (2008) "Timeliness, conservatism and financial transparent firms under the Greek accounting setting”, Review of Accounting and Finance, vol. 7, no. 3: 252-269

Dimitropoulos, P.E., Asteriou, D., Kousenidis, D. \& Leventis, S. (2013) "The impact of IFRS on accounting quality: Evidence from Greece", Advances in Accounting, vol. 29, no. 1: 108-123

Dobre, F., Brad, L. \& Ciobanu, R. (2015) "Timely loss recognition and the value relevance of the Romanian listed companies considering the IFRS approach", Accounting and Management Information Systems, vol. 14, no. 4: 732-747

Eriotis, N., Siriopoulos, C., Vasiliou, D. \& Zisis, V. (2009) "The effect of asymmetric timeliness in the reporting of good and bad news on the properties of profitability: Evidence from Athens Stock Exchange", Managerial Finance, vol. 35, no. 11: 918-929

Gullberg, C. (2016) "What makes accounting information timely?", Qualitative Research in Accounting \& Management, vol. 13, no. 2: 189-215

Istrate, C. (2013) "Impact of IFRS on accounting data-Gray index of conservatism applied to some European listed companies", Annals of the Alexandru Ioan Cuza University-Economics, vol. 60, no. 2: 33-51 
International Accounting Standards Board (2015) International Financial Reporting Standards, Bucureşti: CECCAR

Jaba, E., Robu, I. B., Istrate, C., Balan, C. B. \& Roman, M. (2016) "Statistical Assessment of the Value Relevance of Financial Information Reported by Romanian Listed Companies", Journal for Economic Forecasting, vol. 19, no. 2: $27-42$

Kamarudin, K.A. \& Ismail, W.A.W. (2014) "The risk of earnings quality impairment", Procedia Social and Behavioral Sciences, vol. 145: 226-236

Kim, S., Lee, C. \& Wook Yoon, S. (2013) "Goodwill accounting and asymmetric timeliness of earnings", Review of Accounting and Finance, vol. 12, no. 2: 112-129

Lara, J. M. G. \& Mora, A. (2004) "Balance sheet versus earnings conservatism in Europe", European Accounting Review, vol. 13, no. 2: 261-292

Leventis, S. \& Weetman, P. (2004) "Timeliness of financial reporting: applicability of disclosure theories in an emerging capital market", Accounting and Business Research, vol. 34, no. 1: 43-56

Nobes, C. W. \& Stadler, C. (2015) "The qualitative characteristics of financial information, and managers' accounting decisions: evidence from IFRS policy changes", Accounting and Business Research, vol. 45, no. 5: 572-601

Rodríguez García, M.D.P., Cortez Alejandro, K.A., Méndez Sáenz, A.B. \& Garza Sánchez, H. H. (2017) "Does an IFRS adoption increase value relevance and earnings timeliness in Latin America?", Emerging Markets Review, vol. 30: 155-168

Roychowdhury, S. (2010) "Discussion of: "Acquisition profitability and timely loss recognition", by J. Francis and X. Martin", Journal of Accounting and Economics, vol. 49, no. 1: 179-183

Srivastava, A., Sunder, S. \& Tse, S. (2015) "Timely loss recognition and termination of unprofitable projects", China Journal of Accounting Research, vol. 8, no. 3: 147-167

Toma, C. (2012) "Rolul auditului financiar în creşterea calităţii informaţiilor financiare" [Financial audit's role in increasing the quality of financial information], Audit financiar, vol. 10, no. 95: 5-13

Toma, C., Carp, M. \& Robu, I. B. (2015) "Harnessing Financial Information in Investors Decissions: Accrual Accounting versus Cash Accounting", Procedia Economics and Finance, vol. 26: 1044-1051

*** Order of the Minister of Public Finance no. 2844/2016 for the Approval of Accounting Regulations in Line with International Financial Reporting Standards, published in Monitorul Oficial al României, Part I, no. 687/4.10.2012, with subsequent changes and additions

*** Order of the Minister of Public Finance no. 1.802 / 2014 for the Approval of the Accounting Regulations Concerning Individual Annual Financial Statements and Consolidated Annual Financial Statements, published in Monitorul Oficial al României, Part I, no. 963/30.12.2014, with subsequent changes and additions 
Appendix A. Analysis of the timeliness of earnings depending on financial leverage, the specific features of accounting norms and the field of activity (Basu Model)

\begin{tabular}{|c|c|c|c|c|c|c|c|c|}
\hline \multicolumn{9}{|c|}{$N I_{t}=\alpha_{0}+\alpha_{1} D K_{t}+\alpha_{2} K_{t}+\alpha_{3} K_{t} \times D K_{t}+\varepsilon_{t}$} \\
\hline $\begin{array}{l}\text { Independent } \\
\text { Variables }\end{array}$ & $\mathrm{P}_{1}$ & $\mathrm{P}_{1 \mathrm{Yfe}}$ & $\mathrm{P}_{2}$ & $\mathrm{P}_{2 \mathrm{Yfe}}$ & $\mathrm{P}_{3}$ & $\mathrm{P}_{3 \mathrm{Yfe}}$ & $\mathrm{P}_{4}$ & $\mathrm{P}_{4 \mathrm{Yfe}}$ \\
\hline Intercept & 0.035 & 0.139 & 0.072 & 0.186 & 0.081 & 0.206 & 0.024 & 0.124 \\
\hline$D K$ & -0.166 & -0.212 & -0.169 & -0.217 & -0.160 & -0.212 & -0.167 & -0.224 \\
\hline $\mathbf{K}$ & -0.086 & -0.100 & -0.073 & -0.087 & -0.082 & -0.100 & -0.087 & -0.102 \\
\hline$K_{t} \times D K_{t}$ & 0.168 & 0.291 & 0.120 & 0.229 & 0.185 & 0.291 & 0.169 & 0.292 \\
\hline$F L_{t}$ & & & -0.253 & -0.254 & & & & \\
\hline Norm $_{t}$ & & & & & -0.032 & -0.034 & & \\
\hline Domt $_{t}$ & & & & & & & 0.009 & 0.012 \\
\hline $\mathbf{R}^{2}$ & 0.027 & 0.046 & 0.056 & 0.075 & 0.028 & 0.046 & 0.027 & 0.046 \\
\hline Sig. & 0,101 & 0.100 & 0.010 & 0.013 & 0.171 & 0.100 & 0.183 & 0.154 \\
\hline
\end{tabular}

Yfe - year fix effect

Source: own processing in SPSS 20.0.

Appendix B. Analysis of the simultaneous influence of qualitative factors on the timeliness of reporting earnings (Basu Model)

\begin{tabular}{|c|c|c|c|c|c|c|c|c|c|c|}
\hline \multicolumn{11}{|c|}{$N I_{t}=\alpha_{0}+\alpha_{1} D K_{t}+\alpha_{2} K_{t}+\alpha_{3} K_{t} \times D K_{t}+\varepsilon t$} \\
\hline $\begin{array}{l}\text { Independent } \\
\text { Variables }\end{array}$ & $\mathrm{P}_{1}$ & $\mathrm{P}_{1 \mathrm{Yfe}}$ & $\mathrm{P}_{2}$ & $\mathrm{P}_{2 \mathrm{Yfe}}$ & $\mathrm{P}_{3}$ & $\mathrm{P}_{3 \mathrm{Yfe}}$ & $\mathrm{P}_{4}$ & $\mathrm{P}_{4 \mathrm{Yfe}}$ & $\mathrm{P}_{5}$ & $\mathrm{P}_{5} \mathrm{Yfe}$ \\
\hline Intercept & 0.035 & 0.139 & 0.035 & 0.142 & 0.035 & 0.110 & 0.035 & 0.137 & 0.035 & 0.145 \\
\hline$D K$ & - & - & - & - & - & $\begin{array}{l}- \\
0008\end{array}$ & - & - & - & -0.222 \\
\hline $\mathbf{K}$ & $\begin{array}{l}0.166 \\
- \\
0.086\end{array}$ & $\begin{array}{l}0.212 \\
- \\
0.100\end{array}$ & $\begin{array}{l}0.183 \\
- \\
0.086\end{array}$ & $\begin{array}{l}0.229 \\
- \\
0.100\end{array}$ & $\begin{array}{l}0.170 \\
- \\
0.086\end{array}$ & $\begin{array}{l}0.098 \\
0.928\end{array}$ & $\begin{array}{l}0.165 \\
- \\
0.086\end{array}$ & $\begin{array}{l}0.212 \\
- \\
0.100\end{array}$ & $\begin{array}{l}0.176 \\
-\end{array}$ & -0.101 \\
\hline$K_{t} \times D K_{t}$ & 0.168 & 0.291 & $\begin{array}{l}- \\
0.024\end{array}$ & 0.096 & 0.299 & 0.928 & 0.477 & 0.582 & 0.026 & 0.142 \\
\hline $\begin{array}{l}K_{t} \times D K_{t} \times \\
F L_{t}\end{array}$ & & & 0.682 & 0.653 & & & & & & \\
\hline$K_{t} \times D K_{t} \times$ & & & & & - & - & & & & \\
\hline Norm $_{t}$ & & & & & 0.107 & 0.466 & & & & \\
\hline$K_{t} \times D K_{t} \times$ & & & & & & & - & - & & \\
\hline $\operatorname{Dom}_{t}$ & & & & & & & 0.227 & 0.214 & & \\
\hline$K_{t} \times D K_{t} \times$ & & & & & & & & & 0.389 & 0.357 \\
\hline $\mathrm{FL}_{t} \times \operatorname{Norm}_{t}$ & & & & & & & & & & \\
\hline $\mathbf{R}^{2}$ & 0.027 & 0.046 & 0.041 & 0.059 & 0.027 & 0.051 & 0.030 & 0.049 & 0.037 & 0.054 \\
\hline Sig. & 0,101 & 0.100 & 0.049 & 0.057 & 0.177 & 0.106 & 0.136 & 0.125 & 0.072 & 0.082 \\
\hline
\end{tabular}


Appendix C. Analysis of the timeliness of earnings depending on financial leverage, the specific features of accounting norms and field of activity (Ball and Shivakumar Model)

\begin{tabular}{|c|c|c|c|c|c|c|c|c|}
\hline \multicolumn{9}{|c|}{$\Delta N I_{t}=\beta_{0}+\beta_{1} D \Delta N I_{t-1}+\beta_{2} \Delta N I_{t-1}+\beta_{3} \Delta N I_{t-1} \times D \Delta N I_{t-1}+\varepsilon$} \\
\hline $\begin{array}{l}\text { Independent } \\
\text { Variables }\end{array}$ & $\mathrm{P}_{1}$ & $\mathrm{P}_{1 \mathrm{Yfe}}$ & $\mathrm{P}_{2}$ & $\mathrm{P}_{2 \mathrm{Yfe}}$ & $\mathrm{P}_{3}$ & $\mathrm{P}_{3 \mathrm{Yfe}}$ & $\mathrm{P}_{4}$ & $\mathrm{P}_{4 \mathrm{Yfe}}$ \\
\hline Intercept & 0.037 & 0.025 & 0.038 & 0.026 & 0.068 & 0.082 & 0.050 & 0.038 \\
\hline$D \Delta N I_{t-1}$ & -0.073 & -0.084 & -0.073 & -0.084 & -0.076 & -0.084 & -0.072 & -0.084 \\
\hline$\Delta N I_{t-1}$ & -0.418 & -0.416 & -0.417 & -0.415 & -0.420 & -0.416 & -0.423 & -0.421 \\
\hline$\Delta N I_{t-1} \times D \Delta N I_{t-}$ & -0.176 & -0.182 & -0.178 & -0.184 & -0.182 & -0.182 & -0.170 & -0.176 \\
\hline $\begin{array}{l}1 \\
F L_{t} \\
\text { Norm }_{t}\end{array}$ & & & -0.007 & -0.006 & -0.018 & -0.029 & & \\
\hline $\operatorname{Dom}_{t}$ & & & & & & & -0.010 & -0.10 \\
\hline $\mathbf{R}^{2}$ & 0.373 & 0.381 & 0.374 & 0.381 & 0.378 & 0.381 & 0.375 & 0.383 \\
\hline Sig. & 0.000 & 0.000 & 0.000 & 0.000 & 0.000 & 0.000 & 0.000 & 0.000 \\
\hline
\end{tabular}

Yfe - year fix effect

Source: own processing in SPSS 20.0.

Appendix D. Analysis of the simultaneous influence of qualitative factors on the timeliness of reporting earnings (Ball and Shivakumar Model)

\begin{tabular}{|c|c|c|c|c|c|c|c|c|c|c|}
\hline \multicolumn{11}{|c|}{$\Delta N I_{t}=\beta_{0}+\beta_{1} D \Delta N I_{t-1}+\beta_{2} \Delta N I_{t-1}+\beta_{3} \Delta N I_{t-1} \times D \Delta N I_{t-1}+\varepsilon$} \\
\hline $\begin{array}{l}\text { Independent } \\
\text { Variables }\end{array}$ & $\mathrm{P}_{1}$ & $\mathrm{P}_{1 \mathrm{Yfe}}$ & $\mathrm{P}_{2}$ & $\mathrm{P}_{2 \mathrm{Yfe}}$ & $\mathrm{P}_{3}$ & $\mathrm{P}_{3 \mathrm{Yfe}}$ & $\mathrm{P}_{4}$ & $\mathrm{P}_{4} \mathrm{Yfe}$ & $\mathrm{P}_{5}$ & $\mathrm{P}_{5}$ Yfe \\
\hline Intercept & 0.037 & 0.025 & 0.037 & 0.025 & 0.037 & 0.025 & 0.037 & 0.025 & 0.037 & 0.025 \\
\hline$D \Delta N I_{t-1}$ & $-\overline{0.073}$ & - & $-\overline{0.074}$ & - & $-\overline{0.074}$ & $-\overline{0.084}$ & $-\overline{0.079}$ & $-\overline{0}$ & $-\overline{0.074}$ & -0.085 \\
\hline$\Delta N I_{t-1}$ & $\begin{array}{l}- \\
0.418\end{array}$ & $\begin{array}{l}- \\
0.416\end{array}$ & $\begin{array}{l}- \\
0.418\end{array}$ & $\begin{array}{l}- \\
0.416\end{array}$ & $\begin{array}{l}- \\
0.418\end{array}$ & $\begin{array}{l}- \\
0.418\end{array}$ & $\begin{array}{l}- \\
0.418\end{array}$ & $\begin{array}{l}- \\
0.417\end{array}$ & $\begin{array}{l}- \\
0.418\end{array}$ & -0.416 \\
\hline$\Delta N I_{t-1} \times$ & - & - & - & - & - & - & 1.059 & 1.064 & - & -0.191 \\
\hline $\begin{array}{l}D \Delta N I_{t-1} \\
\Delta N I_{t-1} \times\end{array}$ & 0.176 & 0.182 & $\begin{array}{l}0.185 \\
0.556\end{array}$ & $\begin{array}{l}0.190 \\
0.539\end{array}$ & 0.960 & 1.015 & & & 0.185 & \\
\hline $\begin{array}{l}D \Delta N I_{t-1} \times F L_{t} \\
\Delta N I_{t-1} \times \\
D \Delta N I_{t-1} \times \\
\text { Norm }_{t}\end{array}$ & & & & & 0.624 & 0.661 & & & & \\
\hline $\begin{array}{l}\Delta N I_{t-1} \times \\
D \Delta N I_{t-1} \times\end{array}$ & & & & & & & $-\overline{0.739}$ & $\begin{array}{l}- \\
0.746\end{array}$ & & \\
\hline $\begin{array}{l}\operatorname{Dom}_{t} \\
\Delta N I_{t-1} \times \\
\operatorname{D\Delta NI}_{t-1} \times F L_{t} \\
\times \operatorname{Norm}_{t}\end{array}$ & & & & & & & & & 0.322 & 0.322 \\
\hline $\mathbf{R}^{2}$ & 0.373 & 0.381 & 0.376 & 0.383 & 0.405 & 0.416 & 0.426 & 0.435 & 0.376 & 0.383 \\
\hline Sig. & 0.000 & 0.000 & 0.000 & 0.000 & 0.000 & 0.000 & 0.000 & 0.000 & 0.000 & 0.000 \\
\hline
\end{tabular}

Yfe-year fix effect; Source: own processing in SPSS 20.0. 